\title{
Extraction of Sugars from Black Gram Peels by Reversed-Phase Liquid Chromatography Systems and Identification by TLC and Mass Analysis
}

\author{
C. S. Chidan Kumar ${ }^{1}$, S. Chandraju ${ }^{2}$, R. Mythily ${ }^{2}$, Tarab Ahmad ${ }^{3, *}$, N. M. Made Gowda ${ }^{3}$ \\ ${ }^{1}$ Department of Chemistry, G.Madegowda Institute of Technology, Bharathi Nagar, 571422, Karnataka, India \\ ${ }^{2}$ Department of Studies in Sugar Technology, Sir M. Vishweshwaraya Post-graduate Center, University of Mysore, Tubinakere, Mandya, \\ 571 402, Karnataka, India \\ ${ }^{3}$ Department of Chemistry, Western Illinois University, Macomb, Illinois, 61455, U.SA
}

\begin{abstract}
A rapid and sensitive method for extraction of sugars from the black gram (Vigna mungo) peels was developed using the solvent mixture of $\mathrm{MeOH}$-dichloromethane-water (MDW) $(0.3: 4: 1 \mathrm{v})$ where the polar MeOH-water phase contained sugars. High-performance liquid chromatography (HPLC) with Evaporative Light Scattering Detector (ELSD) coupled with electrospray ionization mass spectrometric (ESI-MS) analysis in the positive ion mode gave mass data which were employed for the characterization of the analyte sugars. In the TLC analysis using the solvent system of $n$-butanol-acetone-pyridine-water $(10: 10: 5: 5, \mathrm{v} / \mathrm{v} / \mathrm{v} / \mathrm{v})$, various standard sugars were spotted along with analyte fractions which indicated the presence of sugars, rhamnose, arabinose, xylose, mannose, galactose and glucose in black gram peels. This is the first assay of the sugar profiles of black gram peels, which can be further evaluated for the sugar composition.
\end{abstract}

Keywords Black Gram Peels, Sugars, LC-MS, Separation, Extraction, TLC

\section{Introduction}

Carbohydrates are among the most abundant compounds in the plant world and the analysis of sugars is of considerable importance to the food and beverage industries[1]. A variety of chromatographic systems including paper and thin-layer chromatography, gas liquid chromatography with flame ionization or mass spectrometric detection, and high-performance liquid (HPLC) can be used to separate and analyse the sugars[1].

Black gram (Vina mungo) originated in India, where it has been in cultivation from ancient times. It is one of the most highly priced pulses of India, where pulses play an integral role in human nutrition. It was also introduced to other tropical areas mainly by Indian immigrants. It occurs throughout Asia and Africa. In India, black gram is Used for preparing papad (a kind of wafer) and barian (spiced balls of ground dal) and together with rice it is sued in preparing dosa and idili. The product sold as "black lentils" is usually the whole urad bean or urad dal. The product sold as "white lentil" is the same lentil without the black skin.Black gram is considered as a demulcent or soothing and cooling

* Corresponding author:

tj-ahmad@wiu.edu (Tarab Ahmad)

Published online at http://journal.sapub.org/aac

Copyright (C) 2012 Scientific \& Academic Publishing. All Rights Reserved agent[2]. It is also an aphrodisiac and nerve tonic[2]. However, excessive use of black gram causes flatulence which can be prevented by adding small amounts of asafoetida, pepper and ginger into culinary preparations[2].

It should not be taken by those who are predisposed to rheumatic diseases and urinary calculi as it contains oxalic acid in high concentration. Black gram dal used in many Indian dishes utilizes mainly the inner portion[3]. The black peel or husk is just thrown as a waste. Black gram, Vigno mungo, husk as food was evaluated for optimum growth and survival of brine shrimp, Artemia sp. (25 days) under laboratory conditions[4]. In another study, the biosorption of heavy metals such as $\mathrm{PB}, \mathrm{Cd}, \mathrm{Zn}, \mathrm{Cu}$ and $\mathrm{Ni}$ was removed efficiently by black gram husk from aqueous solutions[5]. In the present investigation, we have focused mainly on the water soluble sugars present in the husks of black gram, which have wide cost effective applications in the food industry.

The literature survey shows that some sugars from the peels of black gram have been extracted. This investigation is part of a series of studies that have been carried out in our laboratories to understand the nature and composition of sugar profiles in the peels of several fruits including pomegranate, pineapple, banana, black grape and almond[6-11].

\section{Experimental}

\subsection{Instrumentation}


The HPLC system equipped with Waters 2420 Evaporative Light Scattering Detector (ELSD) was used to separate the sugar fractions from extract of the black gram peels An LCMSD/Trap System (Agilent Technologies, 1200 Series) equipped with an electrospray interface was used in the second step. An Agilent 8453 spectrophotometer coupled with a diode array detector was used for the detection of sugars in the fractions. Two chromatographic columns used were: an Adsorbosphere-NH2 column ( $250 \times 4.6 \mathrm{~mm}-5 \mu \mathrm{m})$ and an Atlantis C-18 column (50 x $4.6 \mathrm{~mm}-5 \mu \mathrm{m})$.

\subsection{Materials}

All reagents and solvents used were of HPLC grade. Formic acid, methanol, acetonitrile, dichloromethane and ethanol were purchased from Fisher Scientific Co. To obtain HPLC water, double distilled water from a Milli-Q system (Millipore Lab., Bedford) was subjected to IR irradiation under 3.5 micron filters. All chemicals used in the study were of analytical grade.

\subsection{Extraction}

Selected samples of black gram were sliced, dried under vacuum at $60{ }^{\circ} \mathrm{C}$ for $48 \mathrm{~h}$ and powdered. An amount of $100.0 \mathrm{~g}$ of the raw material was extracted with $75 \mathrm{~mL}$ of double distilled water and $15 \mathrm{~mL}$ of $0.10 \mathrm{~N}$ sulphuric acid and kept at $60^{\circ} \mathrm{C}$ for about $5 \mathrm{~h}$. Contents were cooled and magnetically stirred for $30 \mathrm{~min}$. The extract was treated with barium hydroxide or calcium carbonate as such (2-3 g) and the precipitated barium sulfate or calcium sulfate was filtered off. The resultant syrup was stored at $4^{\circ} \mathrm{C}$ in the dark. The syrup was treated with charcoal (coir pith), agitated for $30 \mathrm{~min}$ and suction-filtered using a sintered glass crucible packed with Silica gel $(230-400$ mesh, $\sim 2 \mathrm{~cm}$ thickness). The filtrate was rotary-evaporated to the dryness. The residue was placed in an air-tight glass container covered with $200 \mathrm{~mL}$ of boiling $80 \% \mathrm{EtOH}$, which dissolved only simple carbohydrates and not the complex polysaccharides.

After simmering for several hours in a steam bath, the container was sealed and stored at room temperature. For the analysis, the sample was homogenized in a blender for 3-5 min (Omni General Laboratory Homogenizer) at high speed and then suction-filtered. After extraction with $80 \%$ EtOH $(2 \times 50 \mathrm{~mL})$, the syrup was concentrated and further extracted in a separatory funnel using a mixture of $\mathrm{MeOH}-$ dichloromethane-water (MDW) $(0.3: 4: 1, \mathrm{v} / \mathrm{v} / \mathrm{v})$. The mixture of MDW was found to give better results as compared to $\mathrm{MeOH}$-chloroform-water (MCW). The organic phase containing the organic impurities was discarded and the $\mathrm{MeOH}-$ water phase containing sugars was evaporated. The residue was oven-dried at $50^{\circ} \mathrm{C}$ overnight to remove the residual solvent and stored at $-2{ }^{\circ} \mathrm{C}$ for chromatographic analysis[Chandraju , 2011].

\subsection{HPLC and LC/MS}

The extracted sugars present in the black gram husks were separated in 26 min by the reversed phase HPLC technique on a column, Adsorbosphere-NH2 $(250 \times 4.6 \mathrm{~mm}$ column) using both isocratic and gradient elutions with acetonitrile/water as the mobile phase. The detector used was a Waters ELSD 2420. In the ELSD detector, the mobile phase is first evaporated and the remaining solid particles of the sample are then carried in the form of a mist into a cell where they are detected by a laser. The separated fractions were subjected to UV analysis using Agilent 8453 spectrophotometer coupled with a diode array detector. The LC-MS analysis was performed with LCMSD/Trap System (Agilent Technologies, 1200 Series) equipped with an electrospray interface. The MS spectra were acquired in the positive ion mode. The mobile phase with $0.10 \%$ formic acid in HPLC grade water (A) and $\mathrm{MeOH}$ (B) was taken in the stationary phase of Atlantis dc- 18 column $(50 \times 4.6 \mathrm{~mm}$ $-5 \mu \mathrm{m})$. The gradient elution program was as follows: $10 \%$ $\mathrm{B}$ to $95 \% \mathrm{~B}$ in $4 \mathrm{~min}, 95 \% \mathrm{~B}$ to $95 \% \mathrm{~B}$ in $1 \mathrm{~min}, 95 \% \mathrm{~B}$ to $10 \% \mathrm{~B}$ in 0.5 min followed by $10 \% \mathrm{~B}$ in $1.5 \mathrm{~min}$ at a flow rate of $1.2 \mathrm{~mL}$ min-1. The column oven temperature was kept at $40^{\circ} \mathrm{C}$ and the injection volume was $2.0 \mu \mathrm{L}$. ass spectra were recorded in the range of $\mathrm{m} / \mathrm{z} 150-1000$. The instrumental parameters were optimized before the run[Chandraju S, 2011].

\subsection{Standard Samples}

Pure saccharide samples of $\mathrm{D}(-)$-arabinose, $\mathrm{D}(-)$-ribose, $\mathrm{D}(+)$-xylose, $\mathrm{D}(+)$-galactose, $\mathrm{D}(+)$-glucose, $\mathrm{D}(+)$-mannose, L(-)-sorbose, $\mathrm{D}(-)$-fructose, $\mathrm{L}(+)$-rhamnose, $\mathrm{D}(+)$-sucrose, $\mathrm{D}(+)$-maltose, and $\mathrm{D}(+)$-lactose were used as standards (Aldrich Chemical Co.).

\subsection{Preparation of Chromatoplates}

The sugar fractions separated from HPLC were concentrated and subjected to thin-layer chromatography (TLC). These fractions were analyzed with one-dimensional TLC on a cellulose MN $300 \mathrm{G}$ layer plate. Each plate was activated at $110^{\circ} \mathrm{C}$ prior to use for $10 \mathrm{~min}$.

\subsection{One-Dimensional Chromatography}

One $\mathrm{mL}$ aqueous solution of 10-mg sample of each of standard sugars or the analyte sugars from HPLC fractions was prepared. After $1 \mu \mathrm{L}$ of each sugar solution was applied, the chromatoplate was placed in a TLC chamber containing the developing solvent and the lid placed. The solvent system used was n-butanol-acetone-pyridine-water (10:10:5:5, $\mathrm{v} / \mathrm{v} / \mathrm{v} / \mathrm{v})$. The plates were developed in an almost vertical position at room temperature[12-15]. After the elution, plate was dried under warm air and sprayed with a mixture of $5 \%$ diphenylamine in $\mathrm{EtOH}, 4 \%$ aniline in $\mathrm{EtOH}$ and $85 \%$ phosphoric acid $(5: 5: 1 \mathrm{v} / \mathrm{v} / \mathrm{v})$. The plate was heated for 10 min at $105^{\circ} \mathrm{C}$ to visualize the colored spots eluted from which Rf values were calculated. 


\section{Results and Discussion}

\subsection{Mass Spectral Analysis}

Figures 1-6 show the following LC peaks: fraction1 at $0.606 \mathrm{~min}$ and $2.637 \mathrm{~min}$; fraction 2 at $0.578 \mathrm{~min}$; fraction3 at $0.592 \mathrm{~min}$; fraction 4 at 0.595 and $2.576 \mathrm{~min}$, fraction5 at $0.584 \mathrm{~min}$; and fraction6 at $0.566 \mathrm{~min}$. The LC-MS data for sugar fractions 1-6 along with the scanned time periods are presented in Table 1 and Figures 1-6.
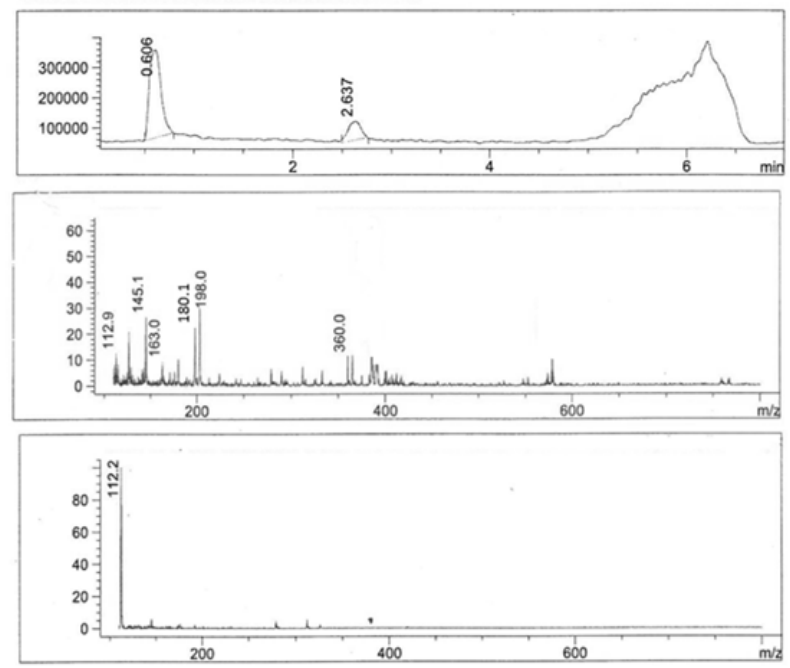

Figure 1. LC-mass spectral data of fraction 1
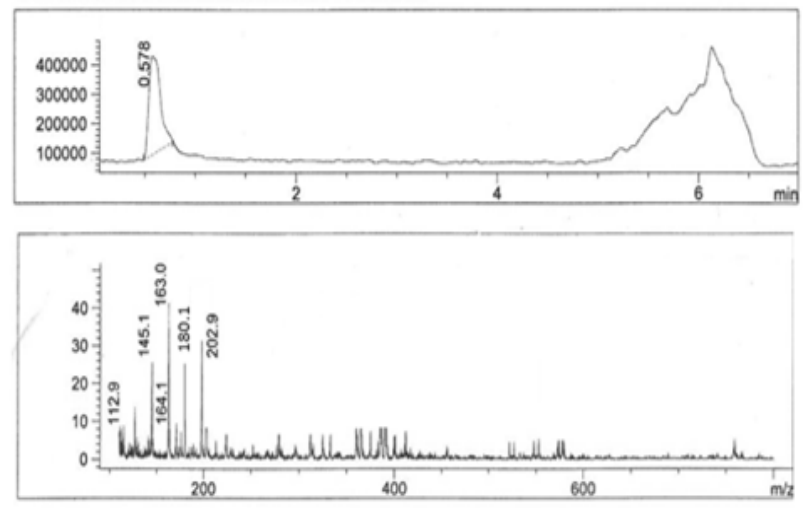

Figure 2. LC-mass spectral data of fraction 2
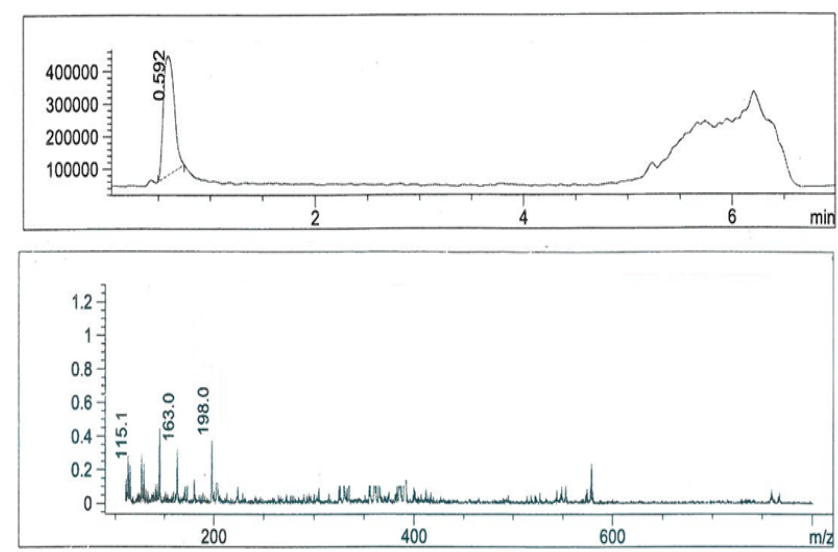

Figure 3. LC-mass spectral data of fraction 3
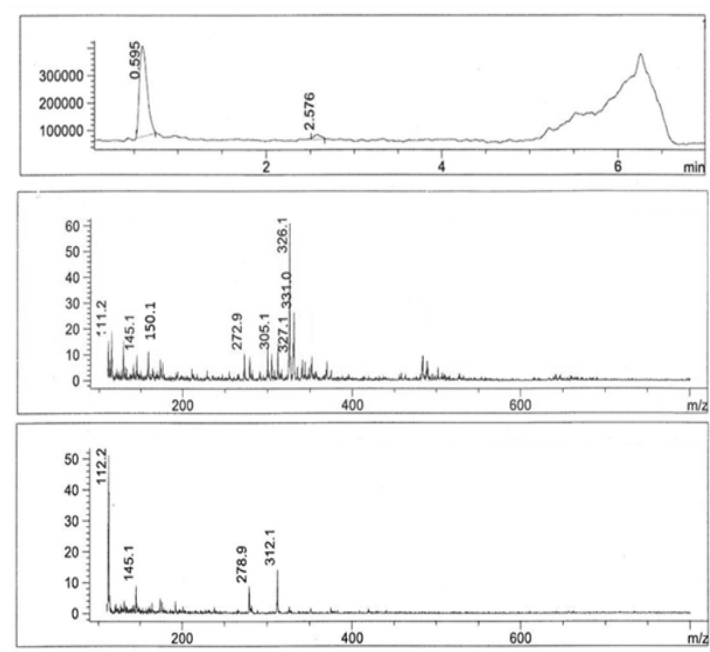

Figure 4. LC-mass spectral data of fraction 4
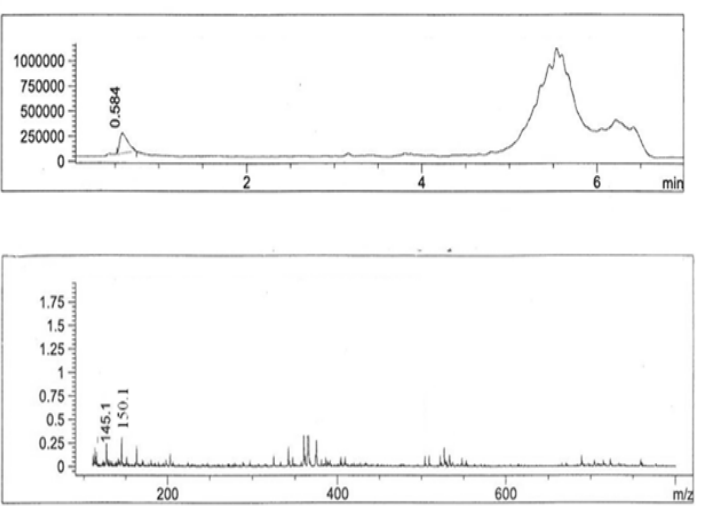

Figure 5. LC-mass spectral data of fraction 5
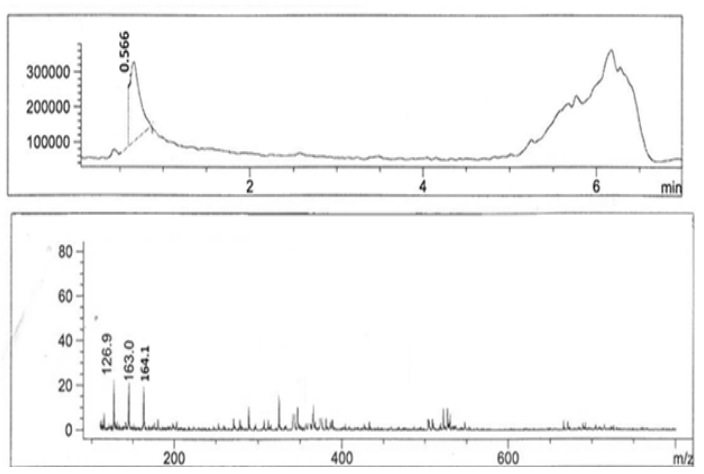

Figure 6. LC-mass spectral data of fraction 6

Table 1. Mass spectral analysis of sugars from black gram peels

\begin{tabular}{|c|c|c|c|}
\hline & $\mathrm{Rt}$ & Time scan & $\mathrm{m} / \mathrm{z}$ \\
\hline \multirow{2}{*}{ Fraction 1 } & 0.606 & $0.507-0.798$ & $\begin{array}{c}112.9,145.1,163.0, \\
180.1,198.0,360.0\end{array}$ \\
\cline { 2 - 4 } & 2.637 & $2.495-2.760$ & 112.2 \\
\hline Fraction 2 & 0.578 & $0.493-0.772$ & $\begin{array}{c}112.9,145.1,163.0, \\
164.1,180.1,202.9\end{array}$ \\
\hline Fraction 3 & 0.592 & $0.493-0.745$ & $115.1,163.0,198.0$ \\
\hline & 0.595 & $0.520-0.745$ & $\begin{array}{c}111.2,145.1,150.1, \\
272.9,305.1,326.1, \\
\text { Fraction 4 }\end{array}$ \\
\cline { 2 - 4 } & 2.576 & $2.508-2.667$ & $112.1,145.1,278.9,312.1$ \\
\hline Fraction5 & 0.584 & $0.520-0.745$ & $145.1,150.1$ \\
\hline Fraction 6 & 0.566 & $0.507-0.600$ & $126.9,163.0,164.1$ \\
\hline
\end{tabular}




\subsection{Thin-Layer Chromatographic Analysis}

Sugars obtained from six HPLC fractions of the black gram peels were spotted on the cellulose layer of TLC plates and the eluted compounds were labelled, F1, F2, F3, F4, F5 and F6 on the chromatogram as shown in Fig 7. Rf values of analyte sugars from different fractions were found to match with the Rf values of the authentic sugar samples of leading to the identification of the former as rhamnose, arabinose, xylose, mannose, galactose and glucose. Table 2 shows $\mathrm{Rf}$ values for the standard sugars and the matching analyte sugars extracted from the black gram skins.

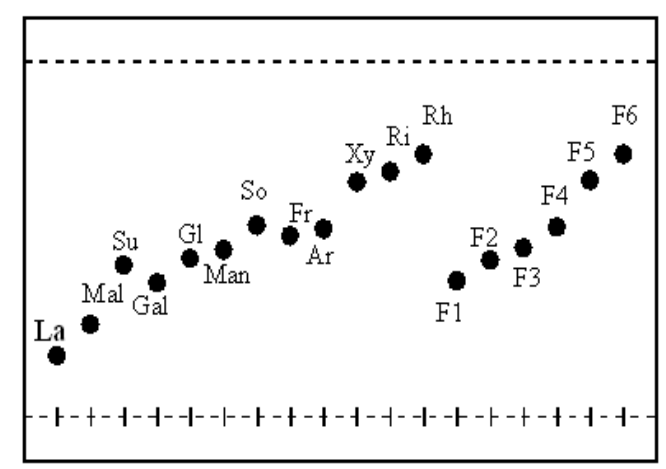

Figure 7. Thin-layer chromatogram for sugars present in black gram husks (standard sugars: La - lactose, So - sorbose, Ar- arabinose, Rh rhamnose, Ri - ribose, Xy-xylose, Gal - galactose, Gl - glucose, Man mannose, $\mathrm{Fr}$ - fructose, $\mathrm{Su}$ - sucrose and Mal -maltose)

Table 2. Comparison of $\mathrm{Rf}$ values of standard sugars with analyte samples from black gram peels

\begin{tabular}{|c|c|c|}
\hline Sugar & $\mathrm{R}_{\mathrm{f}}$ & Analyte* \\
\hline Lactose & 0.17 & - \\
\hline Maltose & 0.26 & - \\
\hline Sucrose & 0.42 & - \\
\hline Galactose & 0.38 & F1 \\
\hline Glucose & 0.44 & $\mathrm{~F} 2$ \\
\hline Mannose & 0.47 & F3 \\
\hline Sorbose & 0.54 & - \\
\hline Fructose & 0.51 & - \\
\hline Arabinose & 0.53 & $\mathrm{~F} 4$ \\
\hline Xylose & 0.66 & F5 \\
\hline Ribose & 0.69 & - \\
\hline Rhamnose & 0.74 & F6 \\
\hline *Sugar frac & g witl & on TLC \\
\hline
\end{tabular}

\section{Conclusions}

In this study, the potential of using a milling agro waste of black gram husks (Vigna mungo) has been assessed as a source of sugars. In batch mode studies, the process involves solvent-solvent extractions and chromatographic analysis. Based on the above studies, a rapid method for the extraction and characterization of water soluble sugars from the black gram (Vigna mungo) husks has been developed. The mixture of $\mathrm{MeOH}$-dichloromethane-water (MDW) gives better results as compared with $\mathrm{MCW}$, where $\mathrm{C}$ is chloroform[15]. Mass spectral and TLC analyses accurately confirm the presence of sugars, rhamnose, arabinose, xylose, mannose, galactose, and glucose.

\section{REFERENCES}

[1] M. Peris-Tortajada and L.M.L.Nollet, Handbook of Food Analysis, 533-550, 1996.

[2] Online: http://www.besthomeremedies.com/herbal_medicine /grains\&pulses/black_gram.htm

[3] B.K. Tiwari, R. Jagan Mohan and B.S. Vasan, "Effect of heat processing on milling of black gram and its end product quality", J. Food Engg., 78(1): 356-360, 2007.

[4] K. Yoganandhan, A.S. Sahul Hameed, "Evaluation of Red Gram, Cajanus cajan and Black Gram, Vigna mungo Husks as Food for Brine Shrimp, Artemia sp., Culture”, J. Appl. Aquaculture, 10(2), 79-85, 2000.

[5] N. Das, P. Karthika, R.Vimala and V. Vinodhini, An Overview, Natural Product Radiance. 7(2), 133, 2008.

[6] S. Chandraju, R. Mythily, and C.S. Chidan Kumar, T. J. Ahmad, and N. M. Made Gowda, "Extraction and Evaluation of a New Acid-Base Indicator from Black Gram Husk (Vigna mungo)", Inorg. Met.-Org. Nano-Met. Chem., 42:498-501, 2012

[7] S. Chandraju, R. Mythily, and C.S.. Chidan Kumar, "Extraction, Isolation and Identification of Sugars from Banana peels (MusaSapientum) by HPLC coupled LC/MS instrument and TLC analysis", J. Chem. Pharm. Res, 3(3), 312-321, 2011.

[8] S. Chandraju, R. Mythily, and C.S.. Chidan Kumar, "Widely applicable method of extracting sugars from the peels of black grape (Vitis vinifera L.) and their analysis using advanced chromatographic techniques". Asian journal of chemistry, 24(5)2170-2172, 2012.

[9] S. Chandraju, R. Mythily, and C.S.. Chidan Kumar,. "Liquid Chromatography/Mass spectroscopy and TLC analysis for the identification of sugars extracted from the outer skin of Almond fruit (Prunus dulcis)", Recent Research in Science and Technology, 3(7), 58-62, 2011.

[10] S. Chandraju, R. Mythily, and C.S.. Chidan Kumar, "Liquid - Liquid Extraction of Sugars from nonedible pineapple (Ananas comosus) and analysis by sophisticated Liquid Chroma

[11] S. Chandraju, R. Mythily, and C.S.. Chidan Kumar, "Separation and identification of simple sugar metabolites from nonedible pomegranate (Punica granatum L.) via TLC and on-line electrospray mass spectrometry", J. Chem. Pharm. Res, 3(4):422-429, 2011.

[12] Baldwin, E. Bell, DJ, Cole's Practical Physiological Chemistry, 189, 1955.

[13] M. Lato, B. Brunelli, and G. Ciuffins, "Bidimensional thin-layer chromatography of carbohydrates on silica gel 
impregnated with boric acid", J. Chromatogr. A, 34, 26-34, 1968.

[14] A. Schweiger, "Separation of simple sugars on celluloselayers", J. Chromatogr. A, 9, 374, 1962.

[15] S.C. Pak, M. Simon, and Landhäusser, "A method for routine measurements of total sugar and starch content in woody plant tissues", Tree Physiology, 24, 1129 -1136, 2004.[16] D.W. Vomhot, T.C. Tucker, "The separation of simple sugars by cellulose by thin-layer chromatography", J. Chromatogr. A, 17, 300-306, 1965.

[16] tography/Mass Spectroscopy and Thin Layer Chromatographic Analysis", Int. J. Curr. Sci. Res. 1(3): 125- 128, 2011. 